\title{
Area-level socioeconomic deprivation and mortality differentials in Thailand: results from principal component analysis and cluster analysis
}

Suchunya Aungkulanon ${ }^{1,2}$, Viroj Tangcharoensathien ${ }^{2}$, Kenji Shibuya $^{3}$, Kanitta Bundhamcharoen $^{2}$ and Virasakdi Chongsuvivatwong ${ }^{1 *}$

\begin{abstract}
Background: Despite achievement of universal health coverage in Thailand, socioeconomic inequality in health has been a major policy concern. This study examined mortality patterns across different socioeconomic strata in Thailand.

Methods: We conducted a cross-sectional analysis of the 2010 Population and Housing Census on area-level socioeconomic deprivation against the 2010 mortality from the vital registration database at the super-district level. We used principal components analysis to construct a socioeconomic deprivation index and K-mean cluster analysis to group socioeconomic status and cause-specific mortality.

Results: Excess mortality rates from all diseases, except colorectal cancer, were observed among super-districts with low socioeconomic status. Spatial clustering was evident in the distribution of socioeconomic status and mortality rates. Cluster analysis revealed that super-districts which were predominantly urban tended to have low all-cause standardize mortality ratio but a high colorectal cancer-specific mortality rate. Deaths due to liver cancer, diabetes, and renal diseases were common in the low socioeconomic super-districts which hosted one third of the total Thai population.

Conclusion: Socially deprived areas have an excess of overall and cause specific deaths. Populations living in more affluent areas, despite low general mortality, still have many preventable deaths such as colorectal cancer. These findings warrant future epidemiological studies investigating various causes of excessive deaths in non-deprived areas and implementation of policies to reduce the mortality gap between rich and poor areas.
\end{abstract}

Keywords: Socioeconomic status, Mortality, Health inequality, Thailand

\section{Background}

Socioeconomic inequality among different regions has been rising in Thailand and in other countries $[1,2]$. Apart from socioeconomic disparities, geographical variations in all causes and cause-specific mortality rates also exist in Thailand [3]. Previous studies revealed high mortality rates in the northern region but high mortality rates due to liver cancer and diabetes in the northeastern

\footnotetext{
*Correspondence: cvirasak@gmail.com

${ }^{1}$ Epidemiology Unit, Faculty of Medicine, Prince of Songkla University,

Songkhla, Thailand

Full list of author information is available at the end of the article
}

region [4]. Bangkok metropolitan area is known to have a low overall mortality rate compared to other regions, but a high rate due to cardiovascular diseases.

Socioeconomic status at the geographical levels has been identified as a major determinant of health in a population [5]. The socioeconomic characteristics of an area influences the health of a population through various mechanisms such as physical characteristics, for example availability of goods and services and environmental pollutants, and social characteristics, for example societal cohesion, collective efficacy (reflecting the ability of members of a community to control the behavior of individuals or groups in the 
community ensuring safety and security) and social support to cope with stress [6].

Socioeconomically disadvantaged areas contribute to higher mortality than the more advantaged areas [7-10]. To date, most of the evidence on neighborhood socioeconomic inequalities in health has been reported from high income countries. This issue remains largely unexplored in low and middle income countries.

Studies of investigating geographical and socioeconomic determinants of health have often applied an area-level deprivation index which is constructed by combining several parameters such as education, income, and various other demographic characteristics [5]. Principal component analysis (PCA) is commonly used to construct deprivation index. This deprivation index can be then used to correlate with health outcomes such as mortality rates.

However, the use of PCA sometimes generates ambiguity due to its over-simplifications [11, 12]. The use of such aggregate measures cannot identify the distinct characteristics attributable to specific geographical areas that can often explain the variations in cause-specific mortality rates. A more complete understanding of mortality patterns by geographical and socioeconomic characteristics should contribute to better planning and equitable resource allocation for different areas.

Cluster analysis is another statistical method which can be used to improve our understanding of the health and socioeconomic situation of a population by summarizing the main patterns across a wide range of variables. Using this approach, the main patterns can be summarized into a series of groups or areas, which can subsequently be classified by their mortality pattern and socioeconomic type [13].
Choropleth maps can be used to display the geographical distribution of measurements of a population such as mortality rate and socioeconomic status. Together with cross-tabulation of mortality rate and socioeconomic status, the map can allow a visualization of the association between the two variables on a spatial dimension, which can then provide evidence for policy makers to invest more in health services to the most disadvantaged regions as well as specific health interventions to reduce cause specific mortality. Such a map will facilitate better targeting of health interventions and resource investments [14]. This study examined the deprivation and cause-specific mortality, mortality clustering, socioeconomic clustering and correlation between mortality clusters and socioeconomic clusters in Thailand.

\section{Methods}

A cross-sectional analysis of two datasets was conducted; the 2010 Census of Population and Housing conducted by the National Statistical Office and mortality records from the Civil Registration and Vital Statistics in 2010. A flowchart of the methodology is shown in Fig. 1, which describes the process of analysis of these two datasets. From the flow chart, four main findings emerge: cause specific standardized mortality ratio (SMR) by deprivation index at the super-district level, mortality clusters, geographical socioeconomic clusters, and a tabulation between geographical socioeconomic and mortality clusters.

\section{Unit of analysis}

In 2010, Thailand was classified as a lower middle-income country with a population of 63 million. There were 77 provinces and 928 administrative districts. The population

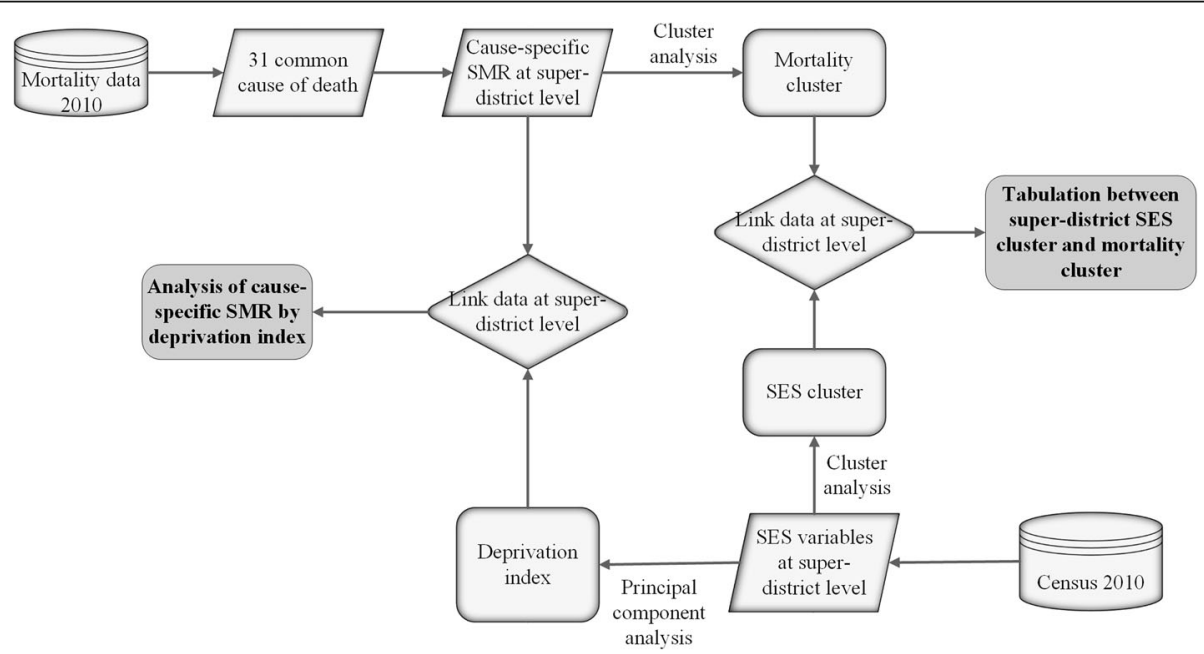

Fig. 1 Methodology flowchart 
of these districts varied substantially, ranging from a minimum of 2253 to a maximum of 492,490 . The significant variation in population size of the districts violates the assumption of equal variance within each unit. To alleviate this violation, we aggregated adjacent districts, thus systematically created what we call super-districts. These super-districts have less variation in population size, thus the mortality rates in areas in these are relatively more stable. A detailed explanation for deriving super-districts is described elsewhere [4]. The 928 administrative districts were aggregated into 331 super-districts, with a median population of 189,067 persons and ranging from 100,970 to 492,490 . These super-district units were used throughout the analysis.

\section{Data sources}

\section{Mortality data}

Population mortality data in 2010 were obtained from the national vital registration system, responsible by the Ministry of Interior, Bureau of Registration Administration. Each record includes date of birth and date, cause and place of death. The description of the cause of death was coded by the Bureau of Policy and Strategy, Ministry of Public Health using the International Classification of Diseases, 10th Revision (ICD-10). Individual mortality was credited to each super-district according to registered place of residence of the deceased. The leading cause of death was categorized by the condensed ICD10 mortality tabulation list 1 , which contains 103 causes of death [15]. We selected the 31 most common causes of death based on mortality in the general population, which covered $95 \%$ of all deaths in 2010 .

Standardized mortality ratios were calculated to compare mortality across super-districts. The numbers of deaths expected in each super-district was calculated by taking the reference from the mortality rates of Thailand for the year 2010, by sex, age and cause of death. Mid-year population data in 2010 was obtained from the Bureau of Registration Administration, Ministry of Interior. The SMR was the main measure of mortality in all subsequent analyses.

\section{Socioeconomic data}

A random weighted sample of $20 \%$ of the 2010 Census of Population and Housing database was obtained from the National Statistics Office, which was the maximum proportion that the research team was allowed to access. This proportion was deemed adequate for the analysis at the super-district level. The census includes the following variables at the household and individual levels: demographic characteristics such as age, gender, nationality, marital status, education level and literacy, occupation and work status, migration characteristics and duration of living in the house, characteristic and tenure of dwelling, and ownership of durable appliances [16]. Income and expenditure information are not included in the Thai census.

Based on previous studies on important socioeconomic indicators which contribute to the construction of the deprivation index [17-28] and availability of the data, we identified 18 socio-demographic variables in the census, listed in Table 1, to construct the deprivation index. Similar to the mortality data, socioeconomic data of individuals and households were aggregated to obtain the proportion of individuals and households at the super-district level. Each aggregated variable was standardized into a z-score and used in the principle component analysis and cluster analysis.

\section{Statistical analysis \\ Principle component analysis}

Principal component analysis (PCA) is a data reduction technique frequently used to create socio-demographic scales or indices [29,30]. In constructing the deprivation index, 18 socioeconomic variables were reduced into a single factor using varimax rotation. Factor scores from the first principal component was designated as the deprivation index. Higher scores correspond to higher levels of deprivation. Super-districts were then classified into quintiles according to their deprivation index. A choropleth map was created to visualize the geographical distribution of socioeconomic deprivation by quintile. PROC FACTOR procedures in SAS version 9.4 was used to conduct the PCA.

\section{Analysis of socioeconomic gradient and cause-specific mortality}

To examine the effect of simplified socioeconomic gradient on mortality, the cause-specific SMR between the two extremes - the top quintile (Q5: most deprived) and the bottom quintile (Q1: least deprived) - were compared to reflect the effect of socioeconomic gradient on cause-specific mortality. Note that this is unlike wealth index quintiles where Q1 represents the poorest group and Q5 represents the richest.

\section{Cluster analysis}

This study adopted the K-means clustering method to separately group super-districts based on socioeconomic status and mortality rate. K-means clustering is a well-known and widely used technique due to its simplicity, robustness, and efficiency when using large datasets [31]. It classifies observations into clusters in which each observation belongs to the cluster with the nearest mean.

The procedure begins with the construction of initial cluster centers. Each super-district is individually relocated to the cluster center that they are located nearest 
Table 1 List of socioeconomic and demographic variables in the census to construct the deprivation index

\begin{tabular}{|c|c|c|c|}
\hline Domain & Variable & Description & Rationale for chosen variable \\
\hline Location & Rural residency & $\%$ of households in non-municipal areas & Literature review [20] \\
\hline \multirow[t]{4}{*}{ Demography } & Unattached elderly & $\begin{array}{l}\% \text { of elderly persons, (aged } 60 \text { and over) } \\
\text { living alone }\end{array}$ & Literature review [17] \\
\hline & $\begin{array}{l}\text { Divorced/separated/ } \\
\text { widowed }\end{array}$ & $\begin{array}{l}\% \text { of females aged } 15 \text { and over who are } \\
\text { separated, divorced or widowed }\end{array}$ & Literature review [27] \\
\hline & Age dependency ratio & $\begin{array}{l}\text { Ratio of the population aged under } 15 \text { or } \\
\text { over } 60 \text { to the the population aged between } \\
15 \text { and } 60\end{array}$ & Available census data \\
\hline & Non-Thai & $\%$ of non-Thai citizens & Available census data \\
\hline \multirow[t]{2}{*}{ Education } & Low education & $\begin{array}{l}\% \text { of persons aged over } 15 \text { years with less } \\
\text { than primary or primary education }\end{array}$ & Literature review [23] \\
\hline & Illiterate & $\%$ of persons aged over 15 years who are illiterate & Literature review [25] \\
\hline Disability & Disabled & $\%$ of persons with visible disabilities & Available census data \\
\hline Employment & Unemployment & $\begin{array}{l}\% \text { of persons aged over } 15 \text { years who are } \\
\text { unemployed }\end{array}$ & Literature review $[19,23,26,27]$ \\
\hline \multirow[t]{6}{*}{ Housing } & No dwelling ownership & $\%$ of not owning their dwelling & Literature review $[19,21,26,28]$ \\
\hline & No vehicle ownership & $\%$ of households without car/motorbike & Literature review $[19,24,28]$ \\
\hline & $\begin{array}{l}\text { No refrigerator } \\
\text { ownership }\end{array}$ & $\%$ of households with no refrigerator & Available census data \\
\hline & No television ownership & $\%$ of households with no television & Available census data \\
\hline & No phone ownership & $\%$ of households without access to phone & Available census data \\
\hline & No internet access & $\%$ of households without access to the Internet & Available census data \\
\hline \multirow[t]{2}{*}{ Crowdedness } & Overcrowded home & $\begin{array}{l}\% \text { of households with more than } 1 \text { person per } \\
\text { bedroom }\end{array}$ & $\begin{array}{l}\text { Literature review and available } \\
\text { census data [24] }\end{array}$ \\
\hline & Children 3+ & $\begin{array}{l}\% \text { of couples who are married with } 3 \text { or more } \\
\text { children }\end{array}$ & [22] \\
\hline $\begin{array}{l}\text { Residential } \\
\text { mobility }\end{array}$ & Migrant & $\begin{array}{l}\% \text { of persons with a different address } 1 \text { year before } \\
\text { the census }\end{array}$ & $\begin{array}{l}\text { Literature review and available census data } \\
{[18,24,26]}\end{array}$ \\
\hline
\end{tabular}

to and then the relocation is assessed to see if it improves the model. Observations are then reassigned until no further improvements can be gained. The cluster algorithm is repeated for all values of $k$ in the range 1 to 9 , where $\mathrm{k}$ represents the number of clusters. The appropriate number of clusters was chosen based the following criteria: 1) generating interpretable clustering patterns; 2) having neither too few nor too many small clusters; and 3) assessing an elbow plot of the overall $\mathrm{R}^{2}$ which can help to determine when a further increase in the number of clusters would result in a relatively little increase in $R^{2}$. PROC FASTCLUS procedures in SAS version 9.4 was used to conduct the cluster analysis. A choropleth map of Thailand was created to visualize the geographical patterns of mortality and socioeconomic status across all super-districts of Thailand.

\section{Association between socioeconomic status and mortality}

Fisher's exact test was used to assess the association between socioeconomic patterns and mortality clusters.

\section{Results}

Deprivation index and cause-specific mortality

The first principal component explained $40.8 \%$ of the total variation in socioeconomic status. This was designate as the deprivation index. A map of super-districts showing variation in the social deprivation gradient is displayed in Fig. 2 with darker hue indicating higher social deprivation. The most deprived areas were mainly located in the northern region and some parts of the northeastern and central regions. Greater Bangkok was the least deprived area.

Table 2 compares cause-specific SMR of Q1 (least deprived super-districts) and Q5 (most deprived superdistricts) by the top 31 causes of mortality. The last column (the extreme ratio between Q5 and Q1) indicates the level of inequality in cause specific mortality between the most and least deprived super-districts.

Cause of death with Q5/Q1 ratios greater than unity suggests a higher risk of death among the deprived compared to the non-deprived super-districts. Of the 31 leading causes of deaths, eight: unspecified causes, liver 


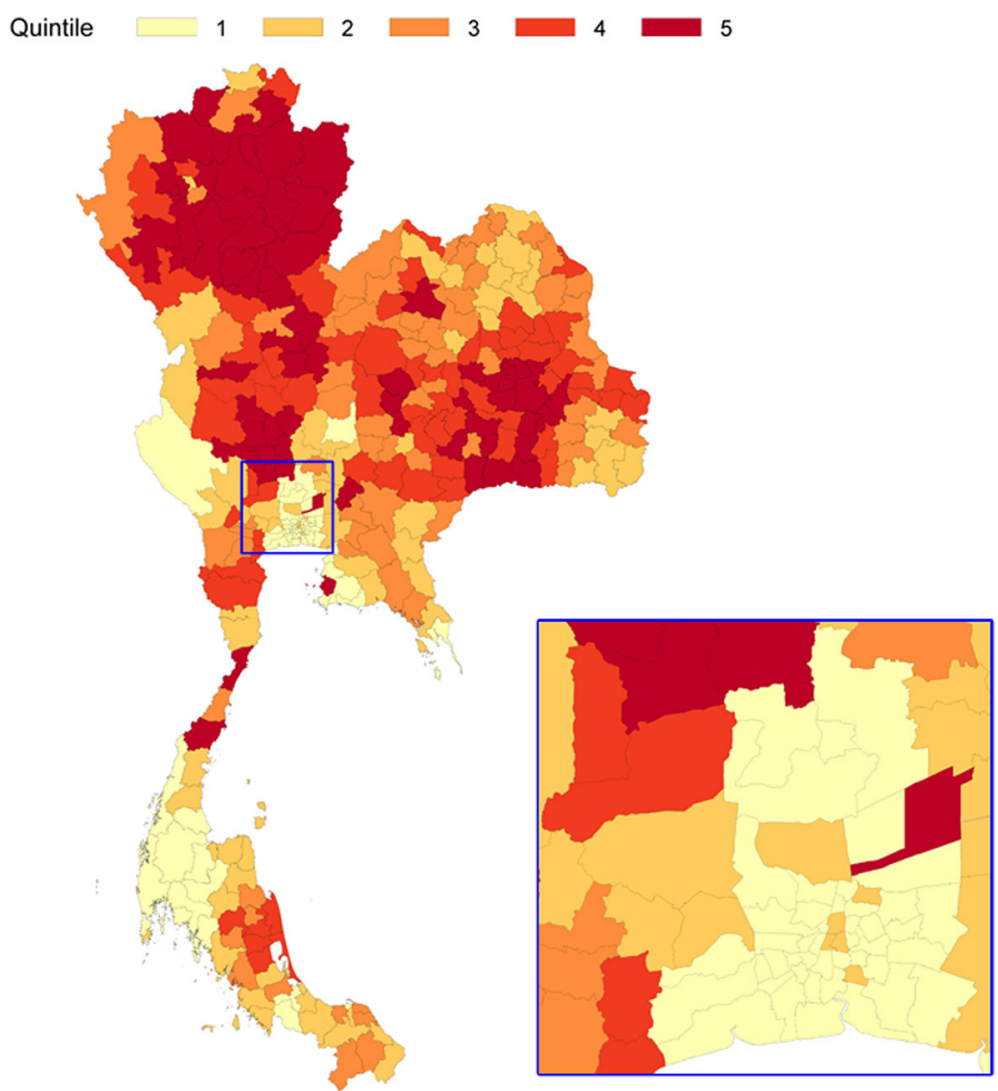

Fig. 2 Geographical distribution of deprivation index

and bile duct cancer, traffic injuries, renal diseases, remainder of diseases of the digestive system, drowning, remainder of diseases of the nervous system, and selfharm, had Q5/Q1 ratios greater than 1.5. Perinatal disorders and colorectal cancer had Q5/Q1 ratios less than 0.66. Ischemic heart disease had higher SMR among the most affluent super-districts.

\section{Mortality clustering}

\section{Selecting the number of clusters}

The elbow plot of $\mathrm{R}^{2}$ by number of clusters shown in Additional file 1: did not exhibit a very strong elbow. The line started to plateau after five clusters. We chose six clusters since it meant that the deep south region was a separate cluster. This is consistent with the fact that the deep south is predominated by the Malay-Muslim ethnic group, which have their own distinct health problems [4].

\section{Cluster description}

Fig. 3 shows a heat map displaying logarithms of the SMR for the 31 disease groups stratified by mortality cluster. The diseases are sorted in decreasing order by their $\mathrm{R}^{2}$ value with the highest at the top.

Cluster 1 consists of super-districts with low mortality (green shade) for many causes. Death from traffic injury and assault were distinctly low whereas death from colon and rectal cancer were notably high.

Cluster 2 contains super-districts having low mortality rates from various causes but assault and traffic injury was exceptionally high.

Cluster 3 includes super-districts with average standardized mortality rates.

Cluster 4 consists of super-districts with high mortality from liver cancer, diabetes, and renal disease. In contrast, mortality due to ischemic heart disease in this cluster was lower than any other cluster. Cluster 5 represents super-districts with a high level of assault and hypertensive heart disease, and extremely low mortality due to self-harm, liver cancer, liver disease, and lung cancer.

Cluster 6 contains super-districts where most causespecific mortalities were higher than the national average.

\section{Interpretation from the cluster analysis}

These six clusters of causes of death were named as follows: cluster 1 "lowest mortality except colorectal cancer", cluster 2 "generally low mortality", cluster 3 "average mortality", cluster 4 "high mortality from liver cancer, diabetes, and renal diseases", cluster 5 "high diversity of mortality", and cluster 6 "high mortality". 
Table 2 Cause-specific mortality by deprivation quintiles

\begin{tabular}{|c|c|c|c|c|c|c|c|c|}
\hline \multirow[t]{2}{*}{ Rank } & \multirow[t]{2}{*}{ Cause of death } & \multirow{2}{*}{$\begin{array}{l}\text { Number } \\
\text { of } \\
\text { deaths }\end{array}$} & \multicolumn{5}{|c|}{ Cause-specific SMR } & \multirow{2}{*}{$\begin{array}{l}\text { Ratio Q5 to Q1 } \\
(95 \% \mathrm{Cl})\end{array}$} \\
\hline & & & $\begin{array}{l}\text { Quintile } 1 \\
\text { (least deprived) }\end{array}$ & Quintile 2 & Quintile 3 & Quintile 4 & $\begin{array}{l}\text { Quintile } 5 \\
\text { (Most deprived) }\end{array}$ & \\
\hline 1 & Unspecified & 154,685 & 0.71 & 0.93 & 1.07 & 1.06 & 1.12 & $1.59(1.47-1.72)$ \\
\hline 2 & Sepsis & 28,959 & 1.10 & 0.87 & 0.86 & 0.81 & 0.95 & $0.86(0.76-0.97)$ \\
\hline 3 & Cerebrovascular diseases & 17,538 & 1.01 & 0.93 & 0.83 & 0.82 & 1.04 & $1.03(0.92-1.14)$ \\
\hline 4 & Liver and bile duct cancer & 16,850 & 0.55 & 0.66 & 0.86 & 1.01 & 1.03 & $1.87(1.49-2.33)$ \\
\hline 5 & Pneumonia & 14,886 & 1.11 & 0.88 & 0.76 & 0.81 & 0.89 & $0.81(0.69-0.94)$ \\
\hline 6 & Traffic injury & 13,772 & 0.50 & 1.03 & 1.07 & 0.99 & 1.05 & $2.08(1.77-2.45)$ \\
\hline 7 & Other external cause & 13,668 & 0.94 & 0.86 & 0.89 & 0.98 & 1.03 & $1.10(0.98-1.24)$ \\
\hline 8 & Other cancers & 13,166 & 0.93 & 0.88 & 0.95 & 1.02 & 0.96 & $1.03(0.92-1.16)$ \\
\hline 9 & Ischemic heart disease & 13,036 & 1.20 & 0.99 & 0.77 & 0.77 & 0.83 & $0.69(0.61-0.79)$ \\
\hline 10 & Renal diseases & 12,853 & 0.61 & 0.82 & 1.00 & 1.03 & 0.98 & $1.59(1.34-1.89)$ \\
\hline 11 & Lung cancer & 9310 & 1.02 & 0.84 & 0.81 & 0.82 & 1.01 & $0.99(0.85-1.14)$ \\
\hline 12 & $\begin{array}{l}\text { Remainder of diseases of } \\
\text { the respiratory system }\end{array}$ & 9243 & 0.78 & 0.89 & 1.04 & 1.00 & 0.98 & $1.27(1.12-1.43)$ \\
\hline 13 & Liver diseases & 7824 & 0.75 & 0.82 & 0.96 & 0.93 & 1.10 & $1.46(1.26-1.69)$ \\
\hline 14 & Diabetes & 6853 & 0.59 & 0.76 & 0.92 & 0.92 & 0.75 & $1.26(0.98-1.62)$ \\
\hline 15 & $\begin{array}{l}\text { Remainder of diseases of } \\
\text { the digestive system }\end{array}$ & 5504 & 0.76 & 0.83 & 0.87 & 0.96 & 1.13 & $1.50(1.30-1.73)$ \\
\hline 16 & $\begin{array}{l}\text { Chronic lower respiratory } \\
\text { diseases }\end{array}$ & 5410 & 0.80 & 0.88 & 0.73 & 0.77 & 1.02 & 1.29 1.06-1.56) \\
\hline 17 & $\begin{array}{l}\text { Remainder of diseases of } \\
\text { the circulatory system }\end{array}$ & 5304 & 0.90 & 0.94 & 0.86 & 0.89 & 1.03 & $1.15(1.02-1.31)$ \\
\hline 18 & Tuberculosis & 4467 & 0.78 & 0.91 & 0.94 & 0.83 & 1.03 & $1.31(1.11-1.55)$ \\
\hline 19 & Drowning & 3984 & 0.67 & 0.82 & 0.96 & 0.91 & 1.14 & $1.70(1.43-2.02)$ \\
\hline 20 & $\begin{array}{l}\text { Remainder of diseases of } \\
\text { the nervous system }\end{array}$ & 3949 & 0.62 & 0.90 & 0.88 & 0.93 & 1.07 & $1.74(1.45-2.09)$ \\
\hline 21 & Self-harm & 3761 & 0.46 & 0.80 & 0.78 & 0.96 & 1.12 & $2.44(1.94-3.07)$ \\
\hline 22 & HIV & 3637 & 0.90 & 0.83 & 0.81 & 0.82 & 1.06 & $1.19(0.99-1.42)$ \\
\hline 23 & Assault & 3300 & 0.62 & 0.97 & 0.81 & 0.72 & 0.64 & $1.03(0.78-1.36)$ \\
\hline 24 & $\begin{array}{l}\text { Remainder of certain infectious } \\
\text { and parasitic diseases }\end{array}$ & 2667 & 0.80 & 0.90 & 0.88 & 0.93 & 0.92 & $1.16(0.96-1.39)$ \\
\hline 25 & $\begin{array}{l}\text { Certain conditions originating } \\
\text { in the perinatal period }\end{array}$ & 2573 & 0.93 & 0.87 & 0.77 & 0.69 & 0.57 & $0.62(0.48-0.79)$ \\
\hline 26 & Hypertensive heart disease & 2478 & 0.77 & 0.77 & 0.72 & 0.65 & 0.79 & $1.02(0.78-1.34)$ \\
\hline 27 & Colon and rectal cancer & 2306 & 1.34 & 0.85 & 0.68 & 0.63 & 0.74 & $0.56(0.45-0.69)$ \\
\hline 28 & Leukemia & 2024 & 0.95 & 0.91 & 0.91 & 0.84 & 0.90 & $0.94(0.80-1.12)$ \\
\hline 29 & $\begin{array}{l}\text { Remainder of diseases of the } \\
\text { genitourinary system }\end{array}$ & 1851 & 0.94 & 0.78 & 0.89 & 0.80 & 0.90 & $0.96(0.77-1.19)$ \\
\hline 30 & $\begin{array}{l}\text { Lip, oral cavity, and pharynx } \\
\text { cancer }\end{array}$ & 1839 & 1.08 & 0.84 & 0.88 & 0.77 & 0.92 & $0.85(0.70-1.03)$ \\
\hline \multirow[t]{2}{*}{31} & $\begin{array}{l}\text { Meninges, brain and other } \\
\text { parts of central nervous system } \\
\text { cancer }\end{array}$ & 1785 & 0.78 & 0.85 & 0.85 & 1.01 & 0.92 & $1.17(0.97-1.43)$ \\
\hline & All causes & 411,279 & 0.88 & 0.93 & 1.07 & 1.06 & 1.09 & $1.25(1.47-1.72)$ \\
\hline
\end{tabular}

Results of this cluster analysis are depicted as a choropleth map and shown in Fig. 4 which suggests a strong geographic clustering of mortality. The location of each cluster is as follows; cluster 1 : Greater Bangkok; cluster 2: southern region excluding the deep south area; cluster 3: central region; cluster 


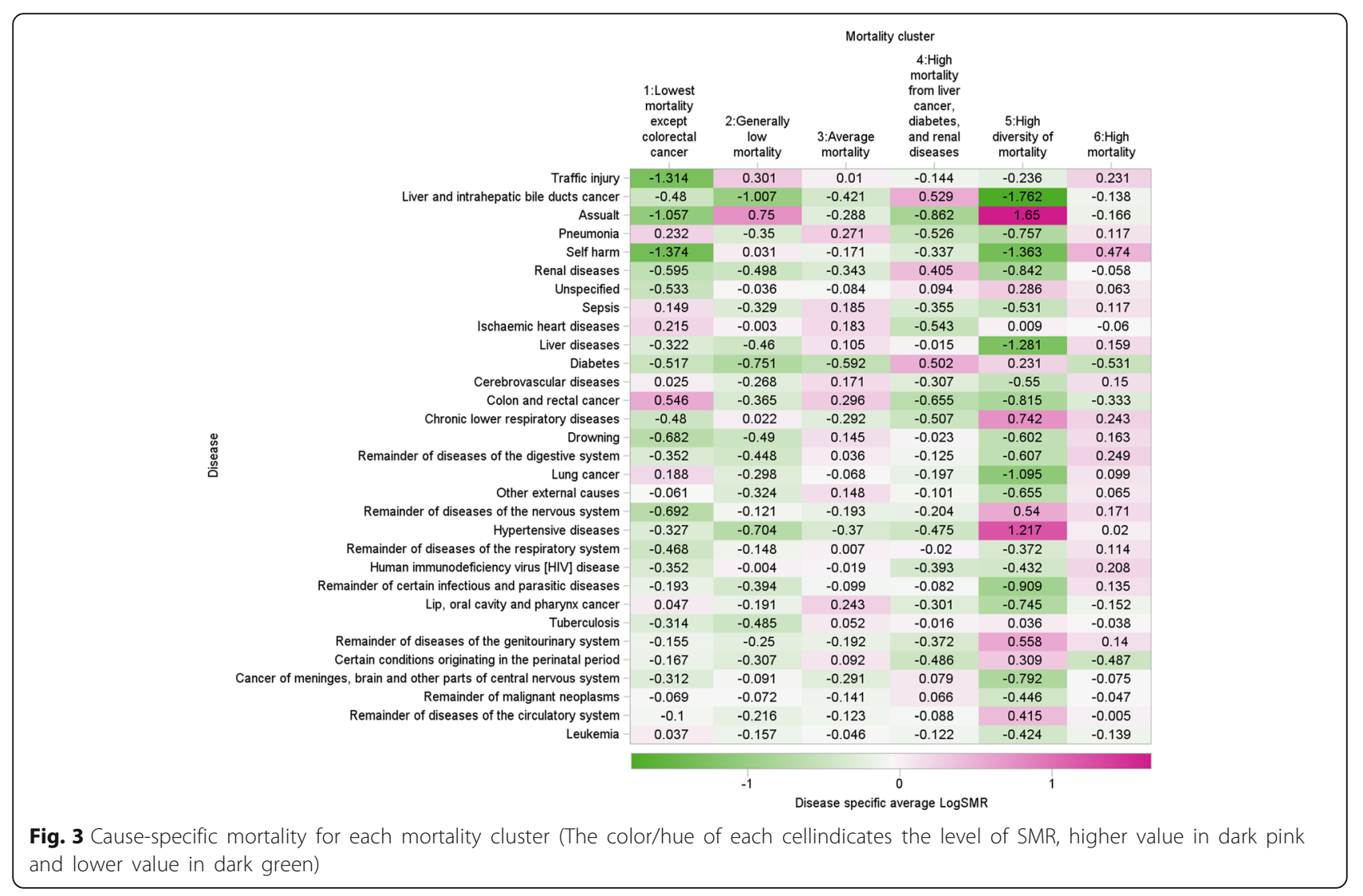

4: northeastern region; cluster 5: deep south region; cluster 6: northern, eastern and western regions.

\section{Socioeconomic clustering}

\section{Selecting the number of clusters}

The elbow plot of $\mathrm{R}^{2}$ for socioeconomic clustering, shown in Additional file 2, had more than one distinct elbow. Possible choices for the number of clusters were 5 , and 7 . We chose 5 clusters as it resulted in being able to distinguish Bangkok from the rest of central Thailand, while 7 clusters resulted in some clusters having too few super-districts.

\section{Cluster description}

Fig. 5 shows a heat map of the cluster analysis of socioeconomic and demographic characteristics for all superdistricts. Five socioeconomic clusters emerged reflecting a gradient of socioeconomic development and urbanization.

Socioeconomic cluster 1 was highly urbanized. This cluster is represented by the well-educated, a high proportion of working aged people, low level of unattached elderly who live alone, and low level of divorced/separated/widowed females. The average household size was small, not crowded and contained a high proportion of people with access to the internet.
Socioeconomic cluster 2 is represented by those with a low overall level of socioeconomic advantages. However, the proportion of residents living in rental dwellings and the concentration of migrants and foreigners were high in this cluster. This is characteristics of industrialized or manufacturing areas.

Socioeconomic cluster 3 fell in-between all other socioeconomic types and showed a slightly higher socioeconomic advantage than the national average.

Socioeconomic cluster 4 represents the disadvantaged areas. The overall socioeconomic levels were below the national average. This socioeconomic cluster was overrepresented by households located in non-municipal areas with larger members per households, overcrowded households, a high proportion of elderly and children, and having limited access to the internet.

Finally, socioeconomic cluster 5 was also characterized as a disadvantaged area with a notably high proportion of low educated and illiterate individuals.

\section{Interpretation from the cluster analysis}

Based on this cluster analysis of socioeconomic profiles of super-districts, we named these five respective clusters as "urbanized", "industrialized", "the middle", "relatively disadvantaged", and "marginalized". Fig. 6 shows a choropleth map of the geographical distribution of the 
1:Lowest mortality except colorectal cancer $(n=39)$

2: Generally low mortality $(n=50)$

3:Average mortality ( $n=66$ )

4: High mortality from liver cancer, diabetes, and renal diseases $(n=96)$

5: High diversity of mortality $(n=11)$

6:High mortality $(n=69)$

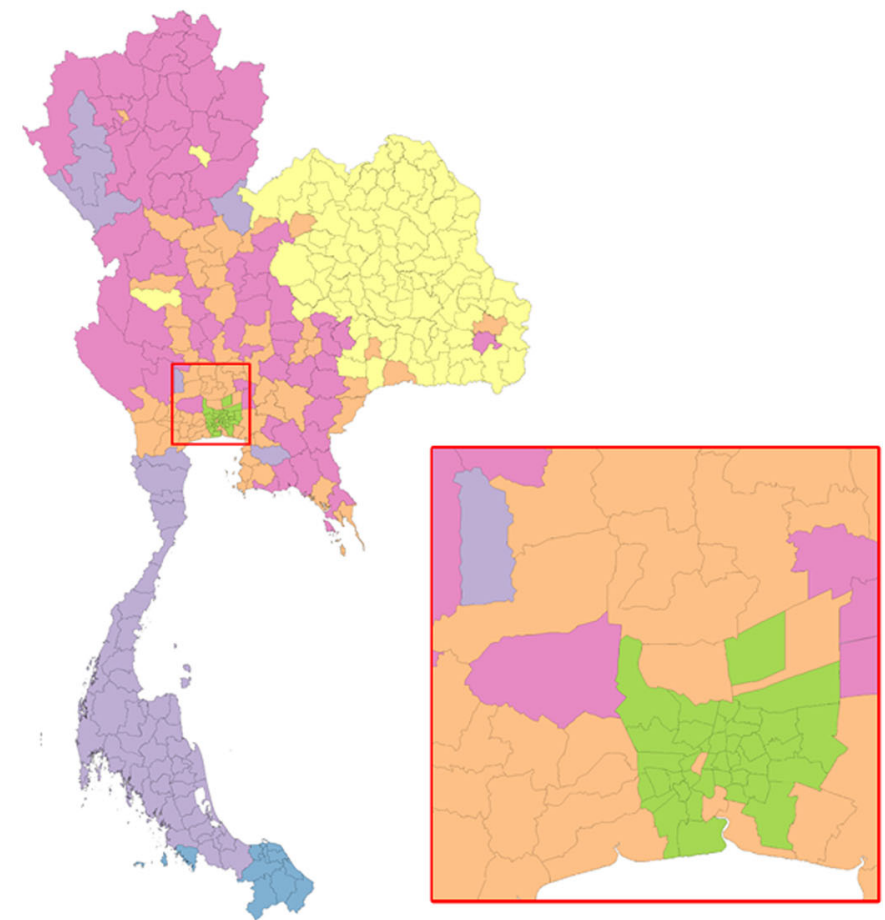

Fig. 4 Geographical distribution of mortality clusters

socioeconomic clusters, suggesting spatial clustering. Socioeconomic cluster 1 (urbanized) contains super-districts located in Bangkok and some provincial capital cities in the southern region; cluster 2 (industrialized) contains super-districts mainly located in the vicinity of Bangkok; cluster 3 (the middle) contains super-districts located in the lower part of the central and eastern regions, and some major cities scattered throughout the country; cluster 4 (relatively disadvantaged) contains super-districts located in the central, northeastern, and southern regions; and cluster 5 (marginalized) contains super-districts mostly located at the border areas of Myanmar and Malaysia.

\section{Association between mortality and socioeconomic clusters}

Table 3 shows a tabulation of the 331 super-districts classified by mortality cluster and socioeconomic cluster. The "urbanized" cluster had the largest proportion of good health while the "marginalized" cluster had the largest percentage of poor health and higher mortality.

About 55\% of all super-districts in Thailand were classified as relatively disadvantaged (182 super districts belonged to cluster 5), of which 90 (27\% of total super-districts) had a higher mortality due to liver cancer, diabetes, and renal diseases. In addition, 24 super-districts (7\%) were classified as marginalized, of which 8 had a high mortality rate. The association between mortality and socioeconomic patterns was highly significant ( $p$-value $<0.0001)$.

\section{Discussion}

Based on principal components analysis, several common diseases were found to have higher excess deaths among the low socioeconomic status super-districts than the more affluent ones. The exception was colorectal cancer, which was more common among the urbanized super-districts. Cluster analysis revealed a clear clustering of cause-specific mortality and socioeconomic status characteristics by geographical area. These cause-specific mortality clusters were associated with different types of socioeconomic clusters.

Principal component analysis and cluster analysis complement each other as analytical tools and can be effectively used to identify clusters based on socioeconomic characteristics. Results from both PCA and cluster analysis on mortality concurred with prior studies which demonstrate that deprived groups have higher overall 


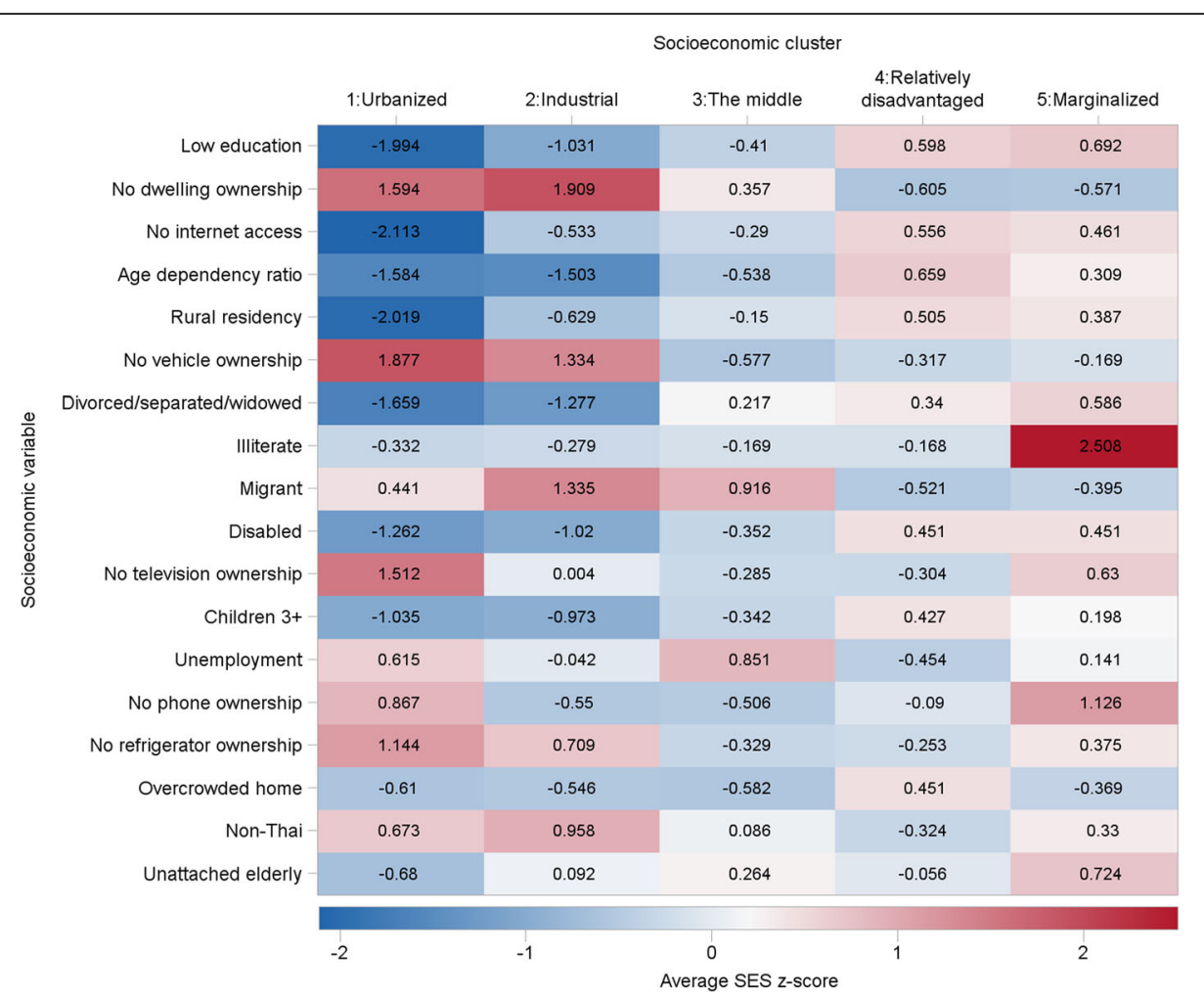

Fig. 5 Average z-scores of socioeconomic and demographic characteristics for each socioeconomic cluster (The color/hue of each cell indicates the level of SES, higher values in dark red and lower values in dark blue)

mortality $[9,32,33]$. Socioeconomic status strongly influences the availability of and access to health services, exposure to environmental hazards, and social cohesion [34]. Several studies in Thailand have also shown that lower socioeconomic groups have poorer health [35, 36], higher mortality [37, 38], a higher prevalence of smoking [39], and a higher prevalence of renal diseases [40] compared with national averages.

Our PCA and cluster analysis found higher mortality rates of colorectal cancer in the more advantaged areas. This finding concurs with previous studies in Thailand and China, which reported a higher incidence and mortality from colorectal cancers in urban areas than in rural areas [41, 42]. However, other studies reported that urban populations and those with high socioeconomic status are more likely to receive colorectal cancer screening and higher frequency of fruit and vegetable consumption, which are known to reduce the risk of colorectal cancer $[43,44]$. Other risk factors may play more important roles in fatal colorectal cancer in urban populations, such as inactive lifestyle, smoking and tobacco use, overweight and obesity, and low-fiber and high-fat diet.

Although Thailand has substantially reduced poverty and achieved considerable gains in the health status of its population over recent decades, poor health attributed from poverty remain significant. Our study found that $55 \%$ of the Thai population resides in relatively disadvantaged areas, for which a high proportion have high mortality due to liver cancer, diabetes, and renal diseases. These areas are exclusively located in the northeastern region. The high mortality of liver cancer geographically coincides with endemic areas of Opisthorchiasis in the northeast [45-47]. Previous reviews reported similar findings that low socioeconomic groups were more likely to die from diabetes and renal diseases $[48,49]$. Also, diabetes and hypertension are two major contributing factors to end stage renal diseases. Effective interventions, both biomedical and behavioral, are required to prevent excess deaths from liver fluke. Mortality in this study was clustered by both overall and cause specific mortality. Populations with high mortality rates were clustered in the northern and remote mountainous areas in the west where livelihoods depend heavily on agriculture as a major source of income. In contrast, areas of generally low mortality were clustered mainly in the southern region where people are better off, relying on tourism and lucrative rubber and palm plantations. The other three clusters were grouped by exceptional excess mortality for one or more specific groups. For example, the extremely higher rates for assaults of "high diversity of mortality" cluster in the deep south region reflected the armed conflict situation, where assaults and 


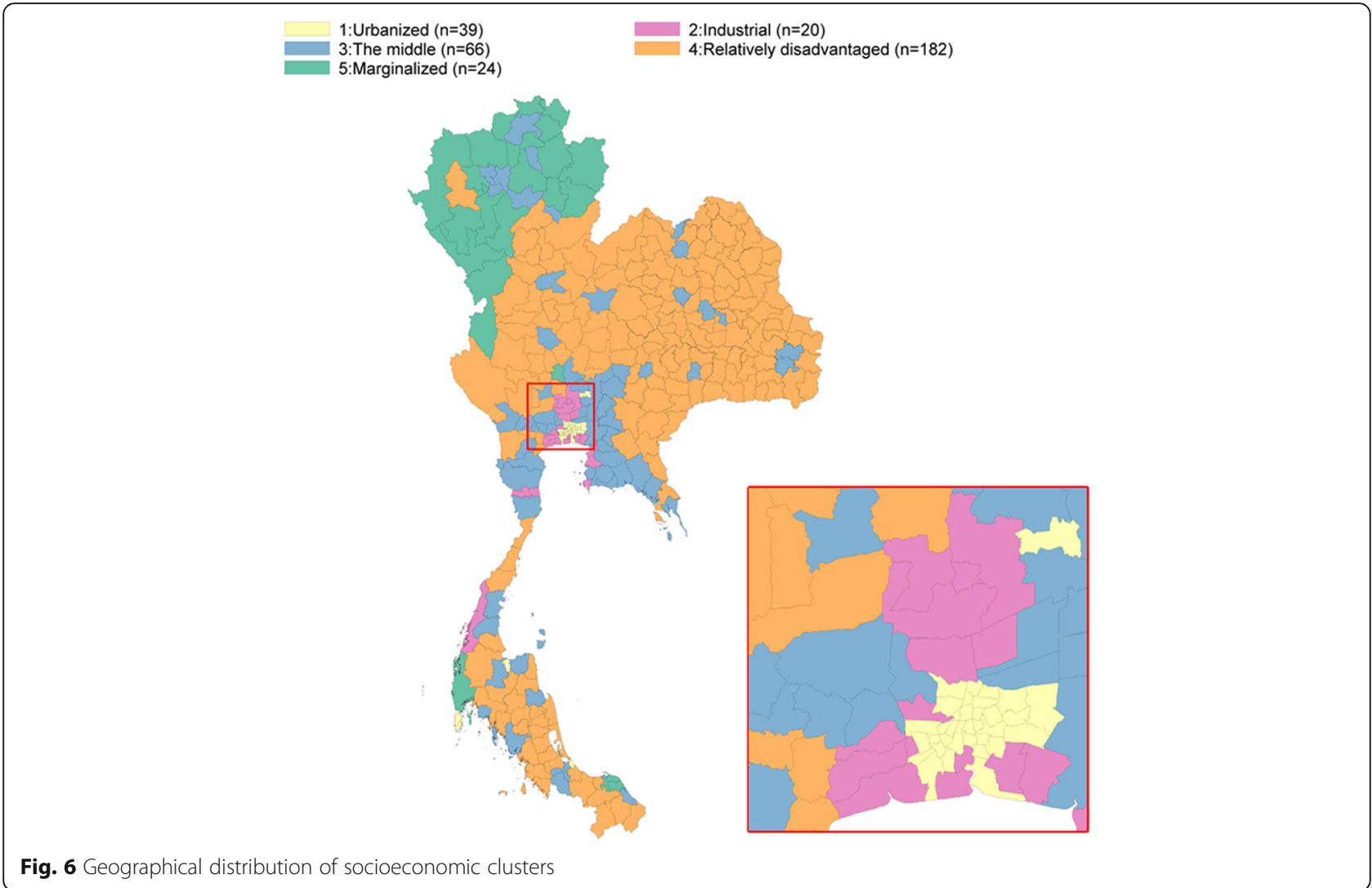

violence have occurred in the southern part of Thailand since 2004 [50].

One possible limitation of this study is that the quality of mortality statistics was considered poor because a large proportion of registered deaths are classified as being due to ill-defined conditions [51, 52]. Unspecified causes of death were also more common in the deprived area whereas perinatal problems were less common. These two phenomena may be explained by different mortality registration biases. The quality of mortality statistics varied by administrative districts in terms of the completeness of death registration and the accuracy of cause-of-death attribution [51-53]. Higher socioeconomic areas had better availability of access to health care and accurate causes of death were more likely to be clinically certified by medical personnel. In contrast, approximately $70 \%$ of deaths in rural areas occurred outside hospitals where cause of death is recorded and coded

Table 3 Distribution of super-districts by six mortality clusters and five socioeconomic clusters $(N=331)$

\begin{tabular}{|c|c|c|c|c|c|c|}
\hline \multirow[t]{2}{*}{ Mortality cluster } & \multicolumn{6}{|c|}{ Socioeconomic cluster } \\
\hline & 1:Urbanized & 2:Industrial & 3:The middle & 4:Relatively disadvantaged & 5:Marginalized & Total \\
\hline $\begin{array}{l}\text { 1:Lowest mortality except } \\
\text { colorectal cancer }\end{array}$ & 32 & 5 & 2 & 0 & 0 & $39(12 \%)$ \\
\hline 2:Generally low mortality & 4 & 2 & 13 & 28 & 3 & $50(15 \%)$ \\
\hline 3:Average mortality & 3 & 13 & 25 & 25 & 0 & $66(20 \%)$ \\
\hline $\begin{array}{l}\text { 4: High mortality from liver } \\
\text { cancer, diabetes, and renal } \\
\text { diseases }\end{array}$ & 0 & 0 & 6 & 90 & 0 & $96(29 \%)$ \\
\hline 5:High diversity of mortality & 0 & 0 & 2 & 6 & 3 & $11(3 \%)$ \\
\hline 6:High mortality & 0 & 0 & 18 & 33 & 18 & $69(21 \%)$ \\
\hline \multirow[t]{2}{*}{ Total } & 39 & 20 & 66 & 182 & 24 & 331 \\
\hline & $12 \%$ & $6 \%$ & $20 \%$ & $55 \%$ & $7 \%$ & $100 \%$ \\
\hline
\end{tabular}

Fisher's exact test with 10,000 Monte Carlo simulations ( $p$-value $<0.0001$ ) 
by non-medical personnel who may not be able to specify an accurate cause of death [54]. Perinatal deaths in rural areas were also more likely to be ignored or unregistered $[55,56]$, thus rural areas will appear to have lower perinatal death rates.

Another limitation is that selection of socioeconomic variables and specific causes of death was critical in this study. Use of different variables or causes may yield different results. We used only the first principal component to construct the deprivation index, thus our index may not have accounted for the contribution of all socioeconomic variables or explained a sufficient amount of variability [57]. The K-means algorithm is a wellknown clustering algorithm due to its robustness and efficiency in analyzing large datasets; however, it requires the number of clusters to be pre-specified. Finding the appropriate number of clusters for a given data set is somewhat arbitrary and the final choice can affect the results. [58].

\section{Conclusion}

Socially deprived areas had an excess of overall and cause specific deaths. Specific policy measures in reducing the socioeconomic gap which contribute to a reduction in health inequity can be guided by the geographical distribution of socioeconomic clusters. The affluent areas, despite low general mortality, still have many preventable deaths such as colorectal cancer. Further epidemiological studies are needed to examine certain causes of excessive deaths in the non-deprived areas.

\section{Additional files}

Additional file 1: Elbow plot of R2 for selection of number of cluster by $\mathrm{K}$-means cluster analysis of mortality data K-means cluster analysis of mortality data. (PNG 16 kb)

Additional file 2: Elbow plot of R2 for selection of number of cluster by K-means cluster analysis of socioeconomic data. (PNG 16 kb)

\section{Abbreviations}

PCA: Principal component analysis; SMR: Standardized mortality ratio

\section{Acknowledgements}

Not applicable.

\section{Funding}

Financial support for the study was provided by the International Health Policy Program.

\section{Availability of data and materials}

The data that support the findings of this study are available from the Ministry of Public Health and National Statistics Office but restrictions apply to the availability of these data, which were used under license for the current study, and so are not publicly available.

\section{Authors' contributions}

SA, VC, VT, KS and KB conceived and designed the study. SA and VC analyzed the data and wrote the manuscript. VT critically reviewed the manuscript. All authors read and approved the final manuscript.
Ethics approval and consent to participate

Ethics approval was obtained from the Ethics Committee of the Faculty of Medicine, Prince of Songkla University, Songkhla, Thailand (reference no. EC 58-299-18-5)

\section{Consent for publication}

Not applicable.

\section{Competing interests}

The authors declare that they have no competing interests.

\section{Publisher's Note}

Springer Nature remains neutral with regard to jurisdictional claims in published maps and institutional affiliations.

\section{Author details}

${ }^{1}$ Epidemiology Unit, Faculty of Medicine, Prince of Songkla University, Songkhla, Thailand. ${ }^{2}$ International Health Policy Program, Ministry of Public Health, Nonthaburi, Thailand. ${ }^{3}$ Department of Global Health Policy, Graduate School of Medicine, University of Tokyo, Tokyo, Japan.

Received: 25 December 2016 Accepted: 22 June 2017

Published online: 03 July 2017

References

1. Cook S, Pincus J. Poverty, inequality and social protection in Southeast Asia: An introduction. J Southeast Asian Econ (JSEAE). 2014:31:1-17.

2. Bird K, Hattel K, Sasaki E, Attapich L. Poverty, income inequality, and microfinance in Thailand. Manila: ADB Southeast Asia Working Paper Series Asian Development Bank; 2011.

3. Faramnuayphol P, Chongsuvivatwong V, Pannarunothai S. Geographical variation of mortality in Thailand. J Med Assoc Thail. 2008;91:1455-60.

4. Aungkulanon S, Tangcharoensathien V, Shibuya K, Bundhamcharoen K, Chongsuvivatwong $V$. Post universal health coverage trend and geographical inequalities of mortality in Thailand. Int J Equity Health. 2016;15:190.

5. Diez Roux AV. Investigating neighborhood and area effects on health. Am J Public Health. 2001;91:1783-9.

6. Meijer M, Rohl J, Bloomfield K, Grittner U. Do neighborhoods affect individual mortality? A systematic review and meta-analysis of multilevel studies. Soc Sci Med. 2012;74:1204-12.

7. Bosma H, van de Mheen HD, Borsboom GJ, Mackenbach JP. Neighborhood socioeconomic status and all-cause mortality. Am J Epidemiol. 2001;153:363-71.

8. Bethea TN, Palmer JR, Rosenberg L, Cozier YC. Neighborhood Socioeconomic Status in Relation to All-Cause, Cancer, and Cardiovascular Mortality in the Black Women's Health Study. Ethn Dis. 2016;26:157-64.

9. Fukuda Y, Nakamura K, Takano T. Higher mortality in areas of lower socioeconomic position measured by a single index of deprivation in Japan. Public Health. 2007;121:163-73.

10. McLoone P, Boddy FA. Deprivation and mortality in Scotland, 1981 and 1991. BMJ. 1994;309:1465-70.

11. Luginaah I, Jerrett M, Elliott S, Eyles J, Parizeau K, Birch S, et al. Health profiles of Hamilton: Spatial characterisation of neighbourhoods for health investigations. GeoJournal. 2001;53:135-47.

12. Vyas S, Kumaranayake L. Constructing socio-economic status indices: how to use principal components analysis. Health Policy Plan. 2006;21:459-68.

13. Harris R, Sleight P, Webber R. Geodemographics, GIS and neighbourhood targeting. West Sussex, England Hoboken, N.J.: Wiley; 2005.

14. Murray CJ, Kulkarni SC, Michaud C, Tomijima N, Bulzacchelli MT, landiorio TJ, et al. Eight Americas: investigating mortality disparities across races, counties, and race-counties in the United States. PLoS Med. 2006;3:e260.

15. World Health Organization. Special tabulation lists for mortality and morbidity; Mortality tabulation list 1. Int Stat Classif Dis Health Relat Probl Tenth Revision. 2004;1:1207-10

16. National Statistical Office. The 2010 population and housing census Bangkok; 2010.

17. Carstairs V. Deprivation indices: their interpretation and use in relation to health. J Epidemiol Community Health. 1995;49(Suppl 2):S3-8. 
18. English PB, Kharrazi M, Davies S, Scalf R, Waller L, Neutra R. Changes in the spatial pattern of low birth weight in a southern California county: the role of individual and neighborhood level factors. Soc Sci Med. 2003;56:2073-88.

19. Gordon D. Census based deprivation indices: their weighting and validation. J Epidemiol Community Health. 1995;49(Suppl 2):S39-44.

20. Hillemeier MM, Weisman CS, Chase GA, Dyer AM. Individual and community predictors of preterm birth and low birthweight along the rural-urban continuum in central Pennsylvania. J Rural Health. 2007;23:42-8.

21. Kaufman JS, Dole N, Savitz DA, Herring AH. Modeling community-level effects on preterm birth. Ann Epidemiol. 2003;13:377-84.

22. Krefis AC, Schwarz NG, Nkrumah B, Acquah S, Loag W, Sarpong N, et al. Principal component analysis of socioeconomic factors and their association with malaria in children from the Ashanti Region. Ghana Malar J. 2010;9:201.

23. Krieger N, Chen JT, Waterman PD, Soobader MJ, Subramanian SV, Carson R. Choosing area based socioeconomic measures to monitor social inequalities in low birth weight and childhood lead poisoning: The Public Health Disparities Geocoding Project (US). J Epidemiol Community Health. 2003;57:186-99.

24. Lalloue B, Monnez JM, Padilla C, Kihal W, Le Meur N, Zmirou-Navier D, et al. A statistical procedure to create a neighborhood socioeconomic index for health inequalities analysis. Int J Equity Health. 2013;12:21.

25. Ocana-Riola R, Saurina C, Fernandez-Ajuria A, Lertxundi A, Sanchez-Cantalejo C, Saez M, et al. Area deprivation and mortality in the provincial capital cities of Andalusia and Catalonia (Spain). J Epidemiol Community Health. 2008;62:147-52

26. Odoi A, Wray R, Emo M, Birch S, Hutchison B, Eyles J, et al. Inequalities in neighbourhood socioeconomic characteristics: potential evidence-base for neighbourhood health planning. Int J Health Geogr. 2005;4:20.

27. Pampalon R, Hamel D, Gamache P, Simpson A, Philibert MD. Validation of a deprivation index for public health: a complex exercise illustrated by the Quebec index. Chronic Dis Inj Can. 2014;34:12-22.

28. Saunders J. Weighted Census-based deprivation indices: their use in small areas. J Public Health Med. 1998;20:253-60.

29. Singh GK. Area deprivation and widening inequalities in US mortality, 19691998. Am J Public Health. 2003;93:1137-43.

30. Messer LC, Laraia BA, Kaufman JS, Eyster J, Holzman C, Culhane J, et al. The development of a standardized neighborhood deprivation index. J Urban Health. 2006;83:1041-62

31. Everitt B. Cluster analysis. 5th ed. Chichester, West Sussex, U.K.: Wiley; 2011.

32. Carstairs $V$, Morris R. Deprivation and mortality: an alternative to social class? Community Med. 1989;11:210-9.

33. Hoffmann R, Borsboom G, Saez M, Mari Dell'Olmo M, Burstrom B, Corman $D$, et al. Social differences in avoidable mortality between small areas of 15 European cities: an ecological study. Int J Health Geogr. 2014;13:8.

34. Adler NE, Newman K. Socioeconomic disparities in health: pathways and policies. Health Aff (Millwood). 2002;21:60-76.

35. Yiengprugsawan V, Lim LL, Carmichael GA, Sidorenko A, Sleigh AC. Measuring and decomposing inequity in self-reported morbidity and selfassessed health in Thailand. Int J Equity Health. 2007;6:23.

36. Somkotra T. Socioeconomic inequality in self-reported oral health status: the experience of Thailand after implementation of the universal coverage policy. Community Dent Health. 2011;28:136-42.

37. Woodward M, Peters SA, Batty GD, Ueshima H, Woo J, Giles GG, et al. Socioeconomic status in relation to cardiovascular disease and causespecific mortality: a comparison of Asian and Australasian populations in a pooled analysis. BMJ Open. 2015;5:e006408.

38. Vapattanawong $P$, Hogan MC, Hanvoravongchai $P$, Gakidou E, Vos T, Lopez $A D$, et al. Reductions in child mortality levels and inequalities in Thailand: analysis of two censuses. Lancet. 2007:369:850-5.

39. Jitnarin N, Kosulwat V, Rojroongwasinkul N, Boonpraderm A, Haddock CK, Poston WS. Socioeconomic status and smoking among thai adults: results of the National Thai Food Consumption Survey. Asia Pac J Public Health. 2011;23:672-81.

40. White SL, McGeechan K, Jones M, Cass A, Chadban SJ, Polkinghorne KR, et al. Socioeconomic disadvantage and kidney disease in the United States, Australia, and Thailand. Am J Public Health. 2008;98:1306-13.

41. Khuhaprema T, Srivatanakul P. Colon and rectum cancer in Thailand: an overview. Jpn J Clin Oncol. 2008;38:237-43.

42. Liu S, Zheng R, Zhang M, Zhang S, Sun X, Chen W. Incidence and mortality of colorectal cancer in China, 2011. Chin J Cancer Res. 2015:27:22-8.
43. Satheannoppakao W, Aekplakorn W, Pradipasen M. Fruit and vegetable consumption and its recommended intake associated with sociodemographic factors: Thailand National Health Examination Survey III. Public Health Nutr. 2009:12:2192-8.

44. Siripongpreeda B, Mahidol C, Dusitanond N, Sriprayoon T, Muyphuag B, Sricharunrat $\mathrm{T}$, et al. High prevalence of advanced colorectal neoplasia in the Thai population: a prospective screening colonoscopy of 1,404 cases. BMC Gastroenterol. 2016;16:101.

45. Sripa B, Kaewkes S, Sithithaworn P, Mairiang E, Laha T, Smout M, et al. Liver fluke induces cholangiocarcinoma. PLoS Med. 2007:4:e201.

46. Joob B. Wiwanitkit V. Opisthorchiasis in Northeastern Thailand: Effect of local environment and culture. Asian Pac J Trop Dis. 2015;5:S96-8.

47. Chitapanarux T, Phornphutkul K. Risk Factors for the Development of Hepatocellular Carcinoma in Thailand. J Clin Transl Hepatol. 2015;3:182-8.

48. Brown AF, Ettner SL, Piette J, Weinberger M, Gregg $E$, Shapiro MF, et al Socioeconomic position and health among persons with diabetes mellitus: a conceptual framework and review of the literature. Epidemiol Rev. 2004;26:63-77

49. Nicholas SB, Kalantar-Zadeh K, Norris KC. Socioeconomic disparities in chronic kidney disease. Adv Chronic Kidney Dis. 2015;22:6-15.

50. Bonura C. Indeterminate geographies of political violence in Southern Thailand. Altern Glob Local Political. 2008:33:383-412.

51. Tangcharoensathien V, Faramnuayphol P, Teokul W, Bundhamcharoen K, Wibulpholprasert S. A critical assessment of mortality statistics in Thailand: potential for improvements. Bull World Health Organ. 2006;84:233-8.

52. Mathers CD, Fat DM, Inoue M, Rao C, Lopez AD. Counting the dead and what they died from: an assessment of the global status of cause of death data. Bull World Health Organ. 2005;83:171-7.

53. Odton $\mathrm{P}$, Bundhamcharoen $\mathrm{K}$, Ueranantasun A. District-level Variations in the Quality of Mortality Data in Thailand. Asia-Pac Popul J. 2010;25:79-90.

54. Rukumnuaykit P. Mortality and causes of death in Thailand: Evidence from the survey of population change and death registration. Asia-Pac Popul J. 2006:21:67-84.

55. Mo-suwan L, Isaranurug S, Chanvitan P, Techasena W, Sutra S, Supakunpinyo C, et al. Perinatal death pattern in the four districts of Thailand: findings from the Prospective Cohort Study of Thai Children (PCTC). J Med Assoc Thail. 2009:92:660-6.

56. Vapattanawong $P$, Prasartkul P. Under-registration of deaths in Thailand in 2005-2006: results of cross-matching data from two sources. Bull World Health Organ. 2011;89:806-12.

57. Sharker MY, Nasser M, Abedin J, Arnold BF, Luby SP. The risk of misclassifying subjects within principal component based asset index. Emerg Themes Epidemiol. 2014;11:6.

58. Kaufman L, Rousseeuw PJ. Finding groups in data: an introduction to cluster analysis: John Wiley \& Sons; 2009.

\section{Submit your next manuscript to BioMed Central and we will help you at every step:}

- We accept pre-submission inquiries

- Our selector tool helps you to find the most relevant journal

- We provide round the clock customer support

- Convenient online submission

- Thorough peer review

- Inclusion in PubMed and all major indexing services

- Maximum visibility for your research

Submit your manuscript at www.biomedcentral.com/submit 